\title{
A la population de s'exprimer!
}

Faut-il livrer aux assureurs la santé publique en Suisse?

A eux de décider qui on soigne, quel hôpital on ferme, quel soignant on engage, quelle somme on consacre aux EMS?

Les médecins ont bien sûr un avis à ce propos. Il est préférable qu'ils restent discrets, sous peine d'être accusés de prêcher pour leur paroisse.

Ces questions regardent la population dans son ensemble, car, malheureusement, chacun sera concerné un jour dans sa chair ou dans son esprit.

Récemment, lors de l'émission TV romande «Droit de Cité», on les a enfin entendus, les représentants des assurés, des patientes, des consommateurs. Ils ont dit à haute et intelligible voix «NON» à un tel projet.

Mesdames, Messieurs, si vous voulez que le corps médical se batte pour vous, il faut que vous le souteniez!

Et vous, médecins, qui avez-vous contacté cette semaine pour faire passer le message?

Docteur Claude Aubert, membre du Comité central de la FMH 